\title{
Dynamic Balance and Neuropathic Changes Following Ankle Proprioceptive Training in Type II Diabetic Patients with Peripheral Neuropathy
}

\author{
Mahdieh Ravand ${ }^{1}$, Mehri Ghasemi2,, Abbas Rahimi ${ }^{3}$, Mohammad Reza Mohajeri-Tehrani ${ }^{4}$ and Alireza Akbarzadeh \\ Baghban $^{5}$ \\ ${ }^{1}$ PhD Candidate, Department of Physical Therapy, Physiotherapy Research Center, School of Rehabilitation, Shahid Beheshti University of Medical Sciences, \\ Tehran, Iran \\ ${ }^{2}$ Assistant Professor, Department of Physical Therapy, Physiotherapy Research Center, School of Rehabilitation, Shahid Beheshti University of Medical Sciences, \\ Tehran, Iran \\ 3 Professor, Department of Physical Therapy, Physiotherapy Research Center, School of Rehabilitation, Shahid Beheshti University of Medical Sciences, \\ Tehran, Iran \\ ${ }^{4}$ Professor, Endocrinology and Metabolism Research Center, Endocrinology and Metabolism Clinical Sciences Institute, Tehran University of Medical Sciences, \\ Tehran, Iran \\ ${ }^{5}$ Professor, Department of Basic Sciences, Proteomics Research Center, School of Rehabilitation, Shahid Beheshti University of Medical Sciences, Tehran, Iran
}

* Corresponding author: Mehri Ghasemi, Department of Physical Therapy, Physiotherapy Research Center, School of Rehabilitation, Shahid Beheshti University of Medical Sciences, Tehran, Iran. Email: mehri_Ghasemi@sbmu.ac.ir

Received 2021 February 01; Revised 2021 February 19; Accepted 2021 April 25.

\begin{abstract}
Background: Peripheral neuropathy is one of the major complications of type II diabetes mellitus. Lower limb proprioceptive impairments due to neuropathy can lead to balance disorders in these patients.

Objectives: The present study aimed to investigate postural stability and neuropathic changes following ankle proprioceptive training in type II diabetic patients with moderate neuropathy.

Methods: The present study was conducted on 24 type II diabetic patients with moderate neuropathy ( 9 females and 15 males) aged 40 65 years (with a mean age of 57.25 years). The treatment consisted of ankle proprioceptive training by the balance board and rocker for 10 consecutive days. Balance indices, including Overall Stability Index (OSI), Anterior-Posterior Stability Index (APSI), and Medial-Lateral Stability Index (MLSI), were measured with Biodex system before and after the treatment, as well as two weeks after treatment in two conditions: condition1: Eyes open, head straight, without using trunk, pelvis, thigh, and knee constrained orthosis. Condition 2: Eyes closed, head back (hyperextension), with using trunk, pelvis, thigh, and knee constrained orthosis. Plate-based Biodex stability was fixed at levels 6 and 8 for condition1 and level 8 for condition 2. The severity of neuropathy was assessed using Valk and Michigan questionnaires, as well as light touch sensation. The analysis of variance with repeated measure was used to evaluate alterations in the stability of patients. Furthermore, the correlation of neuropathic changes and stability parameters were assessed by the Pearson correlation coefficients.

Results: Significant improvements were observed in OSI in all tests of condition 1 (Biodex Balance System (BBS) at level $8(\mathrm{P}=0.001)$ and level $6(\mathrm{P}=0.017$ ), as well as test conditions 2 (level 8; $\mathrm{P}=0.004$ ). After the treatment, at stability level 8 , a significant improvement in the mean values of postural sways in the Anterior-Posterior (AP) direction demonstrated that the ankle strategy was improved in the patients. After the treatment, the scores of the Valk $(\mathrm{P}=0.02)$ and Michigan $(\mathrm{P}=0.001)$ questionnaires were significantly decreased. After two weeks of follow-up, the observed improvement was maintained in the mean values of balance indices (OSI, APSI) and neuropathy due to treatment.

Conclusion: As evidenced by the obtained results, 10 sessions of targeted ankle proprioceptive training improved stability, neuropathy, and light touch sensation of the foot in type II diabetic patients with moderate neuropathy. Foot somatosensory information is one of the most important causes of balance alterations in these patients.
\end{abstract}

Keywords: Ankle proprioception, Balance training, Biodex balance system, Peripheral neuropathy, Type II diabetes

\section{Background}

Peripheral neuropathy is one of the major complications of diabetes (1), leading to progressive loss of vibration, temperature, touch, and proprioception (2), lower limb somatosensory impairment, postural problems, and risk of falls (3). Based on the studies, more than $16 \%$ of diabetic patients suffer from balance disorders (4), increasing to $30 \%-50 \%$ with increased severity of the disease (5), reduced nerve conduction velocity (6), lack of ankle reflexes (7), impaired reflex modulation (8), muscle weakness, especially in ankle dorsal and plantar flexors (9), decreased coordination (7), an increase in extra movements to reach the goal (10), use of inappropriate postural compensatory strategies $(8,11)$, prolonged hyperglycemia, as well as proprioception and exteroception dysfunctions (12). Peripheral neuropathy can lead to balance disorders; moreover, it significantly increases the risk of falls and the appearance of wounds.

Foot sensation and lower leg proprioceptive inputs are two important factors in standing balance, as well as postural control and coordination (11). Bloem et al. (2000) stated that in automatic postural control, afferents of different areas of the body act according to the type of perturbation and the postural needs of individuals. Lower leg proprioception induces reflexes in ankle muscles and helps trigger other automatic postural responses to 
the required postural strategy (13). The diminished lower leg proprioception reduces the accuracy and efficiency of balance responses, such as ankle and step strategies, and leads to poor balance in diabetic patients (14). Diabetic patients with neuropathy are likely to maintain their balance using the hip strategies that mainly require vestibular information (15); therefore, the involvement of ankle strategies is necessary for balance improvement.

Proprioceptive training is effective in the improvement of balance and proprioceptive feedback of legs and ankles. Nonetheless, these exercises were generally performed and usually involved different body systems in balance control (16-19). In general balance training and standing activities, the alteration of the pressure and shear stress of the foot can stimulate the mechanoreceptors at higher neuronal levels. However, the Spatio-temporal coordination of the information received from the visual, vestibular, and somatosensory systems facilitates proper postural control (16). The mere involvement of each of these afferents is important and should be considered in the clinical evaluation of postural disorders of patients with diabetic neuropathy. Since these patients are able to compensate for the lack of sensory systems, the effect of sensory disturbance remains hidden for balance control (20).

Increased co-contraction caused by sway movements in proprioceptive training can enhance mechanoreceptors in muscles, resulting in motor learning and balance improvement (21). In their study, Chong et al. reported that the upper segments have a greater contribution to balance control, compared to foot proprioception, by decreasing the visual and vestibular inputs during proprioceptive training in healthy participants (17). Therefore, the capacity of motor learning and the role of central motor programming are significant in healthy individuals. On the one hand, it is difficult to isolate somatosensory disturbances in controlling the balance of patients with diabetic neuropathy, and there is a regional interdependence between the foot and higher joints $(22,23)$. There exists no study on the effect of mere proprioceptive training on neuropathy in patients with type II diabetes, and many studies referred to a combination of proprioception, balance, strength, whole-body function, especially the trunk, with the interplay of sensory systems and musclestrengthening $(24,25)$.

\section{Objectives}

In light of the aforementioned issues, the present study focused on the dynamic balance and neuropathic changes in type II diabetic patients with peripheral neuropathy following targeted ankle training.

\section{Methods}

\subsection{Study design}

This study was approved by the local Ethics Committee of the Shahid Beheshti University of Medical Sciences (Ethical code: IR.SBMU.RETECH. REC.1397.589). This semi-experimental, singleblinded study was conducted on 24 type II diabetic patients with moderate neuropathy (15 males and 9 females) aged 40-65 years old. The patients were recruited according to inclusion and exclusion criteria by endocrinologist and metabolism physician.

The inclusion criteria were as follows: 1) type II diabetes with a minimum duration of 5 years $(11), 2$ ) Fasting Blood Sugar (FBS) $\geq 7 \mathrm{mmol} / \mathrm{l}$ or $126 \mathrm{mg} / \mathrm{dl}$ $(19), 3)$ Glycated hemoglobin (HbA1c) between 7\% and 9\% (26), 4) Body Mass Index (BMI) between 25 and $\left.29 / 9 \mathrm{~kg} / \mathrm{m}^{2}(27), 5\right)$ neuropathy diagnosed by a score higher than 2 out of the first part and higher than 1 out of the second part in the Michigan Neuropathy Screening Instrument (MNSI) (25) and score between 10-18 in the Valk questionnaire $(28), 6)$ ability to ambulate at least 10 meters without an assistive device (29), 7) strength of ankle dorsal/plantar flexors, invertors/evertors $\geq 3$ by manual muscle testing (29), 8) at least 20/40 score in snellen dominant eye test chart (26),9) lack of foot and ankle ulcers at the time of the study (21), 10) lack of lower extremity sever pain at the time of the study (21), and 11) lack of regular physical training and physiotherapy intervention in the last three months (30). On the other hand, the exclusion criteria entailed: 1) lower extremity fractures and dislocation, 2) surgery or lower extremity amputation, 3) foot ulcers at study time, 4) cardiac autonomic neuropathy, 5) non-diabetic neuropathy, 6) vestibular system disorders, 7) internal ear infections, and 8) other balance disorders (30). Since condition 2 was assessed in the head hyperextension position, the vertebral artery involvement test was performed for all participants, and they were excluded if the results were positive.

\subsection{Measurements}

\subsection{Neuropathy assessment}

The presence and severity of neuropathy were assessed based on the Valk and Michigan questionnaires.

The Valk polyneuropathy questionnaire is a validated test of sensory symptoms, being widely used for monitoring neuropathy in clinical trials. This instrument consists of 10 items on sensory changes $(n=6)$ and neuropathic pain $(n=4)$, with scores ranging from $0-33$. The scores of 0 and 33 represent no neuropathy to severe neuropathy, respectively. The scores of 10-18 are considered moderate neuropathy (28).

The high reliability and accuracy of MNSI have made it a useful screening instrument for diabetic 
patients with neuropathy. The first part of the MNSI contains 15 items on feelings of pain, numbness, and temperature. Items 4 and 10 which examine circulatory disorder and general anesthesia, respectively, are not considered for scoring patients. The second part includes a brief physical examination of the legs and feet, vibration perception test, Achilles tendon reflex, and monofilament test. The sum of scores for each abnormality ranges from 0-1 (31). The scores higher than 7 and 2.5 in the first and second part of the questionnaire, respectively, are indicative of severe neuropathy (32).

In the present study, vibration perception and monofilament tests were used as a part of MNSI. The vibration perception test was measured by a $128 \mathrm{~Hz}$ tuning fork on the big toe, which measures the function of large nerve fibers (33). The vibration score is considered present if there is a difference of fewer than 10 seconds between the time of interruption of vibration perception in the patient's toe and examiner's fingers, reduced if it lasts for 10 seconds or more, and absent if the patient feels nothing (34). Based on monofilament test considerations, in the current study, sensory perception testing was performed with the SemmesWeinstein (SW) 10-g monofilament (35). The lighttouch sensation by a modified SW 10-g monofilament with very soft hair on the back evaluated patients' feet, measuring the function of small nerve fibers. The patient lay down and closed his/her eyes, and correct or incorrect answers were recorded (26).

\subsubsection{Dynamic balance assessments}

Dynamic balance assessment was performed with Biodex Balance System (BBS) (model 945-300; Shirley, New York) in two different stability levels. The BBS calculates Anterior-Posterior Stability Index (APSI), medial-lateral stability index (MLSI), and Overall Stability Index (OSI), which indicates the degrees of tilt about the Anterior/posterior (AP) and Medial-Lateral (ML). Participants were tested in two standing positions on two legs in the following two programs: condition1: Eyes open, head straight, without using trunk, pelvis, thigh, and knee constrained orthosis. Condition 2: Eyes closed, head back, with using trunk, pelvis, thigh, and knee constrained orthosis. In condition 1, patients were asked to look at a fixed point in the center of the screen. The initial foot position on the platform was saved and used during the later sessions. After unlocking the platform, the participant was told to maintain his/her balance for $20 \mathrm{sec}$ and perform three repetitions at the desired stability level with 30 sec of rest in between; thereafter, the average of indices in all three tests was selected. The therapist stood behind the patient to prevent falling on the BBS. The tests controlled by the therapist to keep the patient from falling were eliminated, and the reassessment was performed after the break. All evaluations were performed in four sessions, including before the treatment [baseline (session 1) and two weeks of baseline (session 2)], after treatment (session 3), and two weeks follow-up (session 4). Moreover, repeated measurements were taken before treatment to eliminate the effect of time.

In the present study, the Biodex instability level was fixed at 6 and 8 (level 8 is more stable than level 6) for condition 1 and level 8 for condition 2 since patients had no balance at stability levels below 6 . The effect of vestibular information on postural control is reduced in head hypertension $(36,37)$. In a pilot study, patients with eyes closed and head extension were evaluated in test condition 2 . The head extension to $40^{\circ}$ was optimally challenging with minimal reliance on the vestibular system. Two male and female orthosis of the knight Tailor type were used in the range of BMI, extending from the thoracic to the pelvic region, which was connected to the thigh and knee joints from both sides. This brace was designed to reduce movement in the joints above the ankle (Figure 1).

\subsection{Treatment planning}

The ankle proprioceptive training included exercises on the ankle balance board with standing on two legs and the rocker board in both dorsal/plantar flexion and left/right directions for 10 consecutive days. The results of a study conducted by Akbari et al. revealed that 10 sessions are optimal for proprioceptive training (16). The pattern of training progression during the sessions was eyes open and head forward, eyes closed and head forward, eyes open and head back (hyperextension), and eyes closed and head back. Each exercise was performed 5 times, each taking 15 seconds with 45 -second rest intervals. The intervention was provided based on the patient's development, as increasing the exercise duration and decreasing rest time by approximately 5

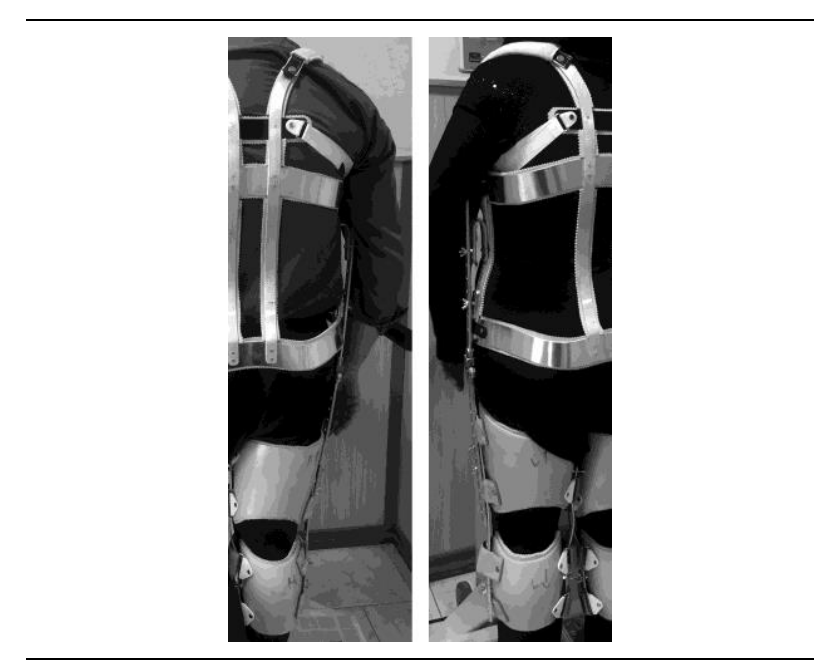

Figure 1. Thoracolumbosacral orthosis with an additional thigh and knee constraint 
sec for every two sessions. The difficulty of the task was also increased with minimal reliance on the vestibular and visual systems during the sessions and decreasing the amount of external support. The protocol described by Chong et al. was employed in the present study (17). During the study period, participants also received a walking program (three times a week for $45 \mathrm{~min}$ ) and general instruction of blood sugar control (38).

\subsection{Statistical analysis}

Statistical analysis was performed in SPSS software (version 25) (IBM Corp., Armonk, N.Y., USA). Kolmogorov-Smirnov analysis was used to check the normality of data distribution. The analysis of variance (ANOVA) with repeated measures was used to evaluate alterations in the stability of patients in different conditions. Pearson correlation coefficients were used to investigate the correlation between stability variables and other parameters.

\section{Results}

A total of 24 patients participated in the present study. The demographic and descriptive characteristics of patients are presented in Table 1. After training (Session 3), patients' neuropathic indices, such as mean scores of Valk and Michigan questionnaires, vibration perception sensation, and light touch sense of the right foot, showed a significant improvement compared to the time before training (Session 1 and 2) (Table 2). The results of vibration perception and light touch sensation tests are illustrated in Figure 2.

\begin{tabular}{lc}
\hline \multicolumn{2}{l}{ Table 1. Description of patients' baseline characteristics $(\mathrm{n}=24)$} \\
\hline Characteristic & $\begin{array}{c}\text { Value } \\
\text { (Mean } \pm \text { SD) }\end{array}$ \\
\hline Males/Females & $15 / 9$ \\
Age(years): & $57.53 \pm 8.44 /$ \\
Males/ & $56.78 \pm 5.11 /$ \\
Females/ & $57.25 \pm 7.25$ \\
Total & $171.14 \pm 37.18$ \\
Fasting blood sugar (mg/dL) & $7.97 \pm 0.68$ \\
(\%) Glycated hemoglobin & $9.13 \pm 3.19$ \\
Duration of disease (years) & $28.10 \pm 1.19$ \\
Body mass index (Kg/m2) & $13.46 \pm 1.21$ \\
Systolic blood pressure in sitting (mm Hg) & $8.58 \pm 1.05$ \\
Diastolic blood pressure in sitting (mm Hg) & $12.08 \pm 1.31$ \\
Systolic blood pressure in supine (mm Hg) & $7.46 \pm 1.10$ \\
\hline Diastolic blood pressure in supine (mm Hg) & \\
\hline
\end{tabular}

The average BBS indices, including OSI, APSI, and MLSI, decreased after 10 sessions of treatment (Table $3)$. After training, the mean OSI in condition 1 at stability levels $8(\mathrm{P}=0.001)$, and $6(\mathrm{P}=0.017)$ and in condition 2 at stability $8(\mathrm{P}=0.004)$ demonstrated a significant improvement, compared to before the training. In addition, OSI mean and standard deviation values in condition 2 were higher than condition 1 . In a general case of conditions 1 and 2, the trend was significant with a p-value lower than 0.05 .

The comparison of APSI at stability level 8 displayed a significant improvement in condition 1 $(\mathrm{P}=0.001)$ and condition $2(\mathrm{P}=0.007)$ after training, compared to before the training; nonetheless, it was not significant at stability level $6(\mathrm{P}=0.115)$. In all conditions of stability level 8 , there was a significant difference between before training (session 1\& 2) and follow-up (session 4) of OSI and APSI. After the

\begin{tabular}{|c|c|c|c|c|c|c|}
\hline variables & $\begin{array}{c}\text { Before } \\
\text { Training } \\
\text { (Session 1\&2) }\end{array}$ & $\begin{array}{c}\text { After } \\
\text { Training } \\
\text { (Session 3) }\end{array}$ & $\begin{array}{c}\text { Follow Up } \\
\text { (Session 4) }\end{array}$ & $\begin{array}{c}\text { P-value } \\
\text { (After Training) } \\
\text { (Session 1\&2) and } \\
\text { (Session 3) }\end{array}$ & $\begin{array}{c}\text { P-value } \\
\text { (Follow Up) } \\
\text { (Session 1\&2) and } \\
\text { (Session 4) }\end{array}$ & $\begin{array}{c}\text { P-value } \\
\text { (Session 3) } \\
\text { and } \\
\text { (Session 4) }\end{array}$ \\
\hline Michigan scores & $5.67 \pm 1.08$ & $3.43 \pm 0.79$ & $3.25 \pm 0.81$ & 0.001 & 0.001 & 0.078 \\
\hline Valk scores & $14.94 \pm .17$ & $13.58 \pm 2.3$ & $9.75 \pm 2.3$ & 0.02 & 0.008 & 0.048 \\
\hline Vibration perception-R & $0.41 \pm 0.19$ & $0.88 \pm 0.22$ & $0.81 \pm 0.32$ & 0.001 & 0.001 & 0.377 \\
\hline Vibration perception-L & $0.66 \pm 0.25$ & $0.83 \pm 0.17$ & $0.80 \pm 0.21$ & 0.005 & 0.004 & 0.412 \\
\hline Light touch sensation-R & $1.48 \pm 0.63$ & $1.92 \pm 0.28$ & $1.92 \pm 0.28$ & 0.001 & 0.001 & - \\
\hline Light touch sensation-L & $1.77 \pm 0.39$ & $1.92 \pm 0.28$ & $1.88 \pm 0.45$ & 0.095 & 0.297 & 0.328 \\
\hline
\end{tabular}

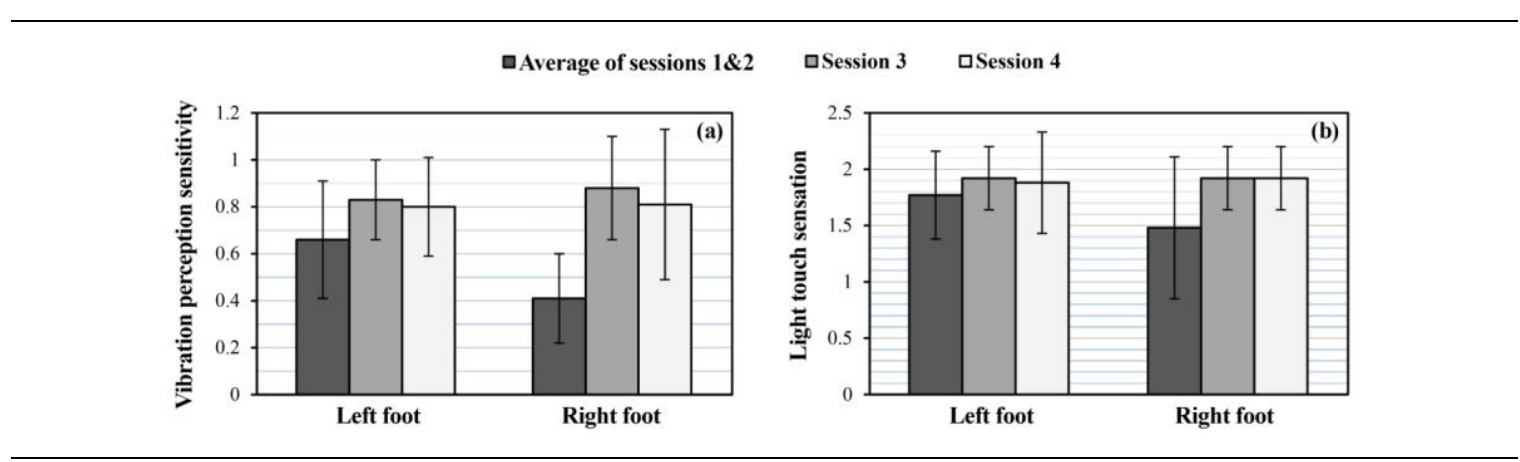

Figure 2. Comparison of Mean and standard deviation for Vibration perception sensitivity (a) and Light touch sensation (b) of left and right foot before and after balance training, as well as after two weeks (follow up) 


\begin{tabular}{|c|c|c|c|c|c|c|c|c|c|c|c|c|c|}
\hline Condition & Index & $\begin{array}{l}\text { Before T } \\
\text { (Sessio }\end{array}$ & $\begin{array}{l}\text { aining } \\
1 \& 2)\end{array}$ & $\begin{array}{r}\text { After T } \\
\text { (Sess }\end{array}$ & $\begin{array}{l}\text { aining } \\
\text { on 3) }\end{array}$ & $\begin{array}{l}\text { Follc } \\
\text { (Sess }\end{array}$ & $\begin{array}{l}v \text { Up } \\
\text { on 4) }\end{array}$ & $\begin{array}{r}P \\
\text { (After } \\
\text { (Sessio } \\
\text { (Se }\end{array}$ & $\begin{array}{l}\text { lue } \\
\text { raining) } \\
\text { 1\&2) and } \\
\text { on 3) }\end{array}$ & $\begin{array}{r}\mathrm{P}- \\
\text { (Fol } \\
\text { (Sessio } \\
\text { (Ses }\end{array}$ & $\begin{array}{l}\text { ue } \\
\text { Up) } \\
\text { z2) and } \\
\text { n 4) }\end{array}$ & $\begin{array}{r}P- \\
\text { (Sessi } \\
\text { (Ses }\end{array}$ & $\begin{array}{l}\text { and } \\
\text { 4) }\end{array}$ \\
\hline \multirow{4}{*}{1} & Level & Level 8 & Level 6 & Level 8 & Level 6 & Level 8 & Level 6 & Level 8 & Level 6 & Level 8 & Level 6 & Level 8 & Level 6 \\
\hline & OSI & $3.51 \pm 1.09$ & $5.03 \pm 1.4$ & $2.73 \pm 1.19$ & $4.14 \pm .68 \mathrm{~s}$ & $2.58 \pm 0.98$ & $1.63 \pm 3.71$ & 0.001 & 0.017 & 0.001 & 0.004 & 0.204 & 0.174 \\
\hline & APSI & $2.49 \pm 0.91$ & $3.85 \pm 1.42$ & $1.54 \pm 0.98$ & $3.21 \pm 1.83$ & $0.93 \pm 1.75$ & $1.16 \pm 2.67$ & 0.001 & 0.115 & 0.001 & 0.102 & 0.292 & 0.199 \\
\hline & MLSI & $2.54 \pm 0.88$ & $3.07 \pm 1.31$ & $2.27 \pm 1.01$ & $2.36 \pm 1.38$ & $0.76 \pm 1.92$ & $1.49 \pm 2.59$ & 0.076 & 0.028 & 0.112 & 0.156 & 0.122 & 0.365 \\
\hline \multirow{4}{*}{2} & Level & \multicolumn{2}{|c|}{ Level 8} & \multicolumn{2}{|c|}{ Level 8} & \multicolumn{2}{|c|}{ Level 8} & \multicolumn{2}{|c|}{ Level 8} & \multicolumn{2}{|c|}{ Level 8} & \multicolumn{2}{|c|}{ Level 8} \\
\hline & OSI & \multirow{2}{*}{\multicolumn{2}{|c|}{$\begin{array}{l}8.62 \pm 2.69 \\
6.97 \pm 2.73\end{array}$}} & \multirow{2}{*}{\multicolumn{2}{|c|}{$\begin{array}{c}6.87 \pm 2.33 \\
5.21 \pm 2.3\end{array}$}} & \multirow{2}{*}{\multicolumn{2}{|c|}{$\begin{array}{l}2.6 \pm 6.41 \\
2.29 \pm 4.5\end{array}$}} & \multirow{2}{*}{\multicolumn{2}{|c|}{$\begin{array}{l}0.004 \\
0.007\end{array}$}} & \multirow{2}{*}{\multicolumn{2}{|c|}{0.004}} & \multirow{2}{*}{\multicolumn{2}{|c|}{0.292}} \\
\hline & APSI & & & & & & & & & & & & \\
\hline & MLSI & \multicolumn{2}{|c|}{$4.85 \pm 1.81$} & \multicolumn{2}{|c|}{$4.37+1.73$} & \multicolumn{2}{|c|}{$2.21 \pm 4.36$} & \multicolumn{2}{|c|}{0.134} & \multicolumn{2}{|c|}{0.212} & \multicolumn{2}{|c|}{0.981} \\
\hline
\end{tabular}
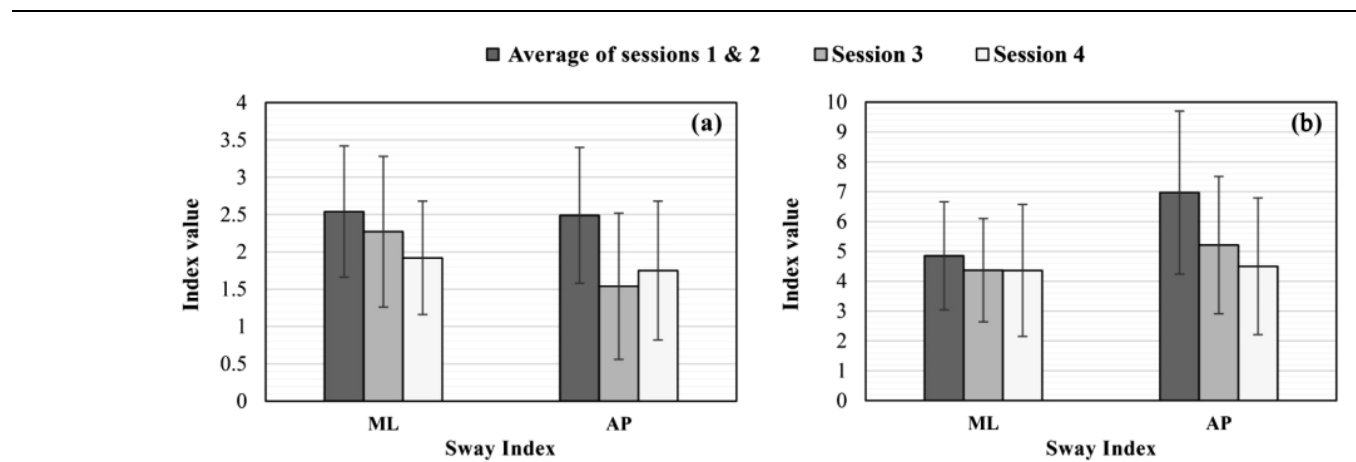

Figure 3. Comparison of Mean and standard deviation for Anterior-Posterior and Medial-Lateral displacements at stability level 8 and condition 1 (a) and condition 2 (b) before and after balance training, as well as after two weeks (follow up)

treatment, the difference in all balance and neuropathy variables between sessions 3 and 4 was not significant, except for the Valk (P=0.048) questionnaire. At this time, the results of the light touch of the right foot were similar to those of the post-treatment session and showed no difference (Table 2 \& 3). In general, after the training, in conditions 1 and 2 , the mean and repeated measurements of stability level 8 demonstrated a significant decrease in APSI values, while this decrease was not significant in MLSI values (Table 3). Figure 3 displays the change in MLSI and APSI for recurrent measurements.

The MNSI was significantly correlated with FBS $(\mathrm{P}=0.002)$ and the light touch of the right foot $(\mathrm{P}=0.001)$; however, no significant correlation was observed between the MNSI and diabetes duration $(\mathrm{P}=0.87)$. In conditions 1 and 2 , the correlation between FBS and OSI ( $\mathrm{P}=0.14 ; \mathrm{P}=0.83$; $\mathrm{P}=0.53)$ was insignificant. The relationship between BMI and OSI was only significant in condition $2(\mathrm{P}=0.046)$. In conditions 1 and 2, the correlation between the MNSI and OSI $(\mathrm{P}=0.001 ; \mathrm{P}=0.003 ; \mathrm{P}=0.036)$, as well as Valk and OSI was significant $(\mathrm{P}=0.002 ; \mathrm{P}=0.01 ; \mathrm{P}=0.041)$.

\section{Discussion}

The main finding of the current study was that targeted ankle proprioceptive training and stimulation of the ankle strategy via small ankle perturbations and movements improved dynamic balance and neuropathic changes in type II diabetic patients with moderate neuropathy. It can be attributed to decreased ankle proprioception in neuropathic patients that might cause balance disorders $(14,39)$, which is further impaired by the reduction of other afferents involved in balance.

Research indicated that the development of an exercise program based on the specificity of training and their functional limitations is necessary for the attainment of desired results $(40,41)$. In the present study, exercise planning and instructions were individually performed based on patients' abilities and conditions. The proprioceptive training protocol used in this study was consistent with the principle of specificity of training. In the exercises of this study, ankle proprioception was not completely separate from hip and knee activity. Based on the results of a study performed by Ko et al., in a weight-bearing position, activities of other joints as a disturbing factor are involved in the study of ankle afferents (42). Although the involvement of other joints could affect the results, the weight-bearing position is more functional. Moreover, the reliability of the ankle proprioception afferents is increased due to foot pressure sensation and higher spindle activity (29).

In contrast to the current study, Kiers et al. reported that ankle proprioception is not targeted by exercises on unstable surfaces, and other systems or central mechanisms play an intermediate role (43). It is worth noting that the referred laboratory study was performed on foam in people with ankle sprain injury, and various factors, such as task, lesion, learning mechanisms, and cognitive factors, have not been considered.

Furthermore, evaluation in different conditions provides a deeper understanding of the relationship between sensory and motor afferents (44). 
Assessment of patient balance in dynamic conditions challenges the feed-forward control system; therefore, motor adaptation is performed to compensate for sensory deficits (45). Consequently, it seems that patients during the study period were able to predict changes and compensate for the manipulation of other sensory systems through learning new motor adaptation mechanisms.

In both conditions 1 and 2, reduction of OSI, APSI, and MLSI was observed after 10 sessions of proprioceptive training, compared to pre-treatment. After treatment at condition 1 and stability level 8, the mean alteration in the APSI was about $38 \%$, while the MLSI showed a change of about $11 \%$. Moreover, in condition 2, without visual and vestibular inputs, patients demonstrated less postural stability in all directions, indicating the role of modulation of the visual and vestibular systems in maintaining the posture of patients (46). One explanation is that patients rely more on other systems to compensate for foot somatosensory impairment. Nevertheless, since patients fear falling, in condition 2 , they had to pay more attention to the foot sensory information which is impaired in people with diabetes.

In addition, in condition 2 with the restriction of higher joints, the mean changes in the APSI and MLSI were about $25 \%$ and $9 \%$, respectively. These findings are in line with those obtained by Fortaleza who reported that in diabetic neuropathic patients with sensory impairment of ankle, AP sway was more affected by visual input than ML (44). As a result, the restriction of visual and vestibular systems, as well as the movement of the upper segments, caused more significant changes in AP direction.

It was revealed that ML displacement indicates postural stability at the level of the hip, and AP displacement suggests stability at the level of the ankle (47). In the present study, greater alterations of APSI were probably due to increased ankle stability and strengthening the ankle strategy in our exercise training. Moreover, the lack of improvement in APSI at stability level 6 indicated that our ankle strategy training alone may not be sufficient in balance control, and the hip strategy may be required. It can be ascribed to greater surface displacements, which can increase surface shear forces and hip muscle activity. Similar results were observed in a study carried out by Horak et al. (1990) (15).

Significant results of vibration perception, light touch sensation, as well as the severity of neuropathy pointed to improved function of small and large fiber neuropathy. Although not all patients showed a complete recovery of protective sensation evaluated by monofilament test, most of them reported a marked decrease in the number of sites involved in the foot. Before the treatment, the significant relationship of OSI with Valk and Michigan questionnaires represented the destructive effects of neuropathy on balance, while this relationship after treatment indicated the positive effects of neuropathy on balance.

The findings of the present research were in agreement with those reported in previous studies $(10,16,21)$ regarding the major role of lower limb somatosensory in the balance control of diabetic patients. Previous studies referred to delayed onset of muscle activity in response to unexpected perturbations of the support surface in these patients $(48,49)$. Sensory impairments associated with neuropathy can increase time delay in the feedback loop. Moreover, they make it difficult to respond to the external perturbations, and consequently, disturb the balance control (50). The results of a study performed by Kim et al. revealed that increased accuracy of ankle proprioceptive threshold reduces postural sways (50). Therefore, it is possible that the development of neuromuscular function following exercise improves patients' balance. Furthermore, an improvement might be achieved in ankle range of motion or stiffness. However, these hypotheses were not investigated in the current study. It is believed that regardless of the presence of visual and vestibular input, the foot somatosensory deficits should be immediately considered since the compensation of visual and vestibular afferents maintains balance.

Despite the obtainment of desired results in the present study, it seems that two weeks follow-up period was insufficient for the assessment of treatment stability, and more time was needed. Furthermore, a significant decrease in Valk questionnaire scores two weeks after the treatment may be attributed to the reduction of neuropathic pain and the frequency of occurrence of their symptoms. Although physical activity improves the proprioception of the lower extremity, the effects of learning during the test should be considered. In the present study, the manual muscle test was not sufficient alone. Moreover, the measurement of motor nerve conduction velocity was not performed to confirm the possibility of motor myopathy. In addition, the effect of patients' cognitive factors on balance and ability to overcome perturbations was not investigated. When patients had similar BMI, fat mass distribution was not assessed as an effective factor in balance indices. Although in the current study, slow and small ankle movements were used purposefully with an emphasis on ankle strategy, the strategy can change to maintain balance if necessary.

\section{Conclusion}

The enhancement of stability in diabetic patients with moderate neuropathy was observed in all test conditions during sessions. After training using the ankle proprioceptive approach, the improvement of the APSI was significant, pointing to the importance of ankle strategy in these patients. Regardless of the 
presence or absence of visual and vestibular systems, the foot somatosensory afferents appeared to perform a crucial role in balance control.

\section{Acknowledgments}

The authors' deepest appreciation goes Dr. Mehdi Rezaei for his assistance in orthosis affairs and all those who participated in this research project.

\section{Footnotes}

Conflicts of Interest: The authors declare that they have no conflict of interest regarding the publication of the present article.

\section{References}

1. van Dieren S, Beulens JW, van der Schouw YT, Grobbee DE, Neal B. The global burden of diabetes and its complications: an emerging pandemic. Eur J Cardiovasc Prev Rehabil. 2010;17(Suppl 1):S3-8. doi: 10.1097/01.hjr.0000368191. 86614.5a. [PubMed: 20489418].

2. Shun CT, Chang YC, Wu HP, Hsieh SC, Lin WM, Lin YH, et al. Skin denervation in type 2 diabetes: correlations with diabetic duration and functional impairments. Brain. 2004;127 (Pt 7):1593-605. doi: 10.1093/brain/awh180. [PubMed: 15128619].

3. Yamamoto R, Kinoshita T, Momoki T, Arai T, Okamura A, Hirao $\mathrm{K}$, et al. Postural sway and diabetic peripheral neuropathy. Diabetes Res Clin Pract. 2001;52(3):213-21. doi: 10.1016/ s0168-8227(01)00236-4. [PubMed: 1132309].

4. Stevens KN, Lang IA, Guralnik JM, Melzer D. Epidemiology of balance and dizziness in a national population: findings from the English Longitudinal Study of Ageing. Age Ageing. 2008;37(3):300-5. doi: 10.1093/ageing/afn019. [PubMed: 18270246].

5. Cimbiz A, Cakir O. Evaluation of balance and physical fitness in diabetic neuropathic patients. J Diabetes Complications. 2005; 19(3):160-4. doi: 10.1016/j.jdiacomp.2004.06.005. [PubMed: 1586606].

6. Gutierrez EM, Helber MD, Dealva D, Ashton-Miller JA, Richardson JK. Mild diabetic neuropathy affects ankle motor function. Clin Biomech (Bristol, Avon). 2001;16(6):522-8. doi: 10.1016/s0268-0033(01)00034-1. [PubMed: 11427295].

7. Centers for Disease Control and Prevention. National diabetes fact sheet. Georgia: Centers for Disease Control and Prevention; 2010.

8. Francia P, Gulisano M, Anichini R, Seghieri G. Diabetic foot and exercise therapy: step by step the role of rigid posture and biomechanics treatment. Cur Diabetes Rev. 2014;10(2): 86-99. doi: 10.2174/1573399810666140507112536. [PubMed: 24807636].

9. Andreassen CS, Jakobsen J, Andersen H. Muscle weakness: a progressive late complication in diabetic distal symmetric polyneuropathy. Diabetes. 2006;55(3):806-12. doi: 10.2337/ diabetes.55.03.06.db05-1237. [PubMed: 16505247].

10. Fahmy IM, Ramzy GM, Salem NA, Ahmed GM, Mohammed AA. Balance disturbance in patients with diabetic sensory polyneuropathy. Egypt J Neurol Psych Neurosurg. 2014;51(1):21-9.

11. Salsabili H, Bahrpeyma F, Forogh B, Rajabali S. Dynamic stability training improves standing balance control in neuropathic patients with type 2 diabetes. J Rehabil Res Dev. 2011;48(7):775-86. doi: 10.1682/jrrd.2010.08.0160. [PubMed: 21938664].

12. Dobretosv M, Romanovsky D, Stimers J. Early diabetic neuropathy: triggers and mechanisms. World J Gastroenterol. 2007;13(2):175-91. doi: 10.3748/wjg.v13.i2.175. [PubMed: 17226897].

13. Bloem BR, Allum JH, Carpenter MG, Honegger F. Is lower leg proprioception essential for triggering human automatic postural responses? Exp Brain Res. 2000;130(3):375-91. doi: 10.1007/s002219900259. [PubMed: 10706436].

14. Moslemi-Haghighi F, Ghafarinejad F, Hemmati L, Saadat Z, Oorangi Z, Torabi S, et al. Evaluation of ankle joint proprioception and balance in patients with type 2 diabetes and healthy subjects. J Rehabil Sci Res. 2015;2(1):17-9. doi: 10.30476/JRSR.2015.41068.

15. Horak FB, Nashner LM, Diener HC. Postural strategies associated with somatosensory and vestibular loss. Exp Brain Res. 1990;82(1):167-77. doi: 10.1007/BF00230848. [PubMed: 2257901].

16. Akbari M, Jafari H, Moshashaee A, Forugh B. Do diabetic neuropathy patients benefit from balance training? I Rehabi Res Dev. 2012;49(2):333-8. doi: 10.1682/jrrd.2010.10.0197. [PubMed: 22773533].

17. Chong RK, Ambrose A, Carzoli J, Hardison L, Jacobson B. Source of improvement in balance control after a training program for ankle proprioception. Percept Mot Skills. 2001;92(1):265-72. doi: 10.2466/pms.2001.92.1.265. [PubMed: 11322594].

18. Kruse RL, Lemaster JW, Madsen RW. Fall and balance outcomes after an intervention to promote leg strength, balance, and walking in people with diabetic peripheral neuropathy: "feet first" randomized controlled trial. Phys Ther. 2010;90(11):1568-79. doi: 10.2522/ptj.20090362. [PubMed: 20798179].

19. Allet L, Armand S, de Bie RA, Golay A, Monnin D, Aminian K, Staal JB, et al. The gait and balance of patients with diabetes can be improved: a randomised controlled trial. Diabetologia 2010;53(3):458-66. doi: 10.1007/s00125-009-1592-4. [PubMed: 19921145].

20. Najafi B, Bharara M, Talal TK, Armstrong DG. Advances in balance assessment and balance training for diabetes. Diabetes Manage. 2012;2(4):293-308. doi: 10.2217/dmt.12.38.

21. El-Wishy A, Elsayed E. Effect of proprioceptive training program on balance in patients with diabetic neuropathy: a controlled randomized study. Bull Facul Physical Ther. 2012;17(2):1-8.

22. Corriveau H, Prince F, Hebert R, Raiche M, Tessier D, Maheux P, et al. Evaluation of postural stability in elderly with diabetic neuropathy. Diabetes Care. 2000;23(8):1187-91. doi: 10.2337/diacare.23.8.1187. [PubMed: 10937520].

23. Rao S, Riskowski J, Hannan MT. Musculoskeletal conditions of the foot and ankle: assessments and treatment options. Best Pract Res Clin Rheumatol. 2012;26(3):345-68. doi: 10.1016/ j.berh.2012.05.009. [PubMed: 22867931].

24. Santos AA, Bertato FT, Montebelo MI, Guirro E. Effect of proprioceptive training among diabetic women. Braz J Physical Ther. 2008;12(3):183-7. doi: 10.1590/S1413-35552008000 300005.

25. Sartor CD, Hasue RH, Cacciari LP, Butugan MK, Watari R, Pássaro AC, et al. Effects of strengthening, stretching and functional training on foot function in patients with diabetic neuropathy: results of a randomized controlled trial. $B M C$ Musculoskelet Dis. 2014;15:137-13. doi: 10.1186/1471-247415-137. [PubMed: 24767584].

26. Salek S, Bahrpeyma F, Mohajeri-Tehrani MR. Intermittent pneumatic compression therapy improves functional and dynamic balance and neuropathy severity in neuropathic patients with type 2 diabetes. Int $J$ Diabetes Dev Ctries. 2015;35(3):439-48. doi: 10.1007/s13410-015-0378-0.

27. Shah A, Parthasarathi D, Sarkar D, Saha CG. A comparative study of body mass index (BMI) in diabetic and nondiabetic in Nepalese population. Kathmandu Univ Med J. 2006;4(1):4-10. [PubMed: 18603858].

28. Valk GD, Grootenhuis PA, Bouter LM, Bertelsmann FW Complaints of neuropathy related to the clinical and neurophysiological assessment of nerve function in patients with diabetes mellitus. Diabetes Res Clin Pract. 1994;26(1):2934. doi: 10.1016/0168-8227(94)90136-8. [PubMed: 7875047].

29. Son J, Ashton-Miller JA, Richardson JK. Do ankle orthoses improve ankle proprioceptive thresholds or unipedal balance in older persons with peripheral neuropathy? Am J Phys Med Rehabil. 2010;89(5):369-75. doi: 10.1097/PHM.0b013e3181d89861. 
[PubMed: 20407302].

30. Kutty NAM, Majida NA. Effects of multisensory training on balance and gait in persons with type 2 diabetes: a randomised controlled trial. Disabil CBR Inclusive Dev. 2013;24(2):79-91. doi: 10.5463/DCID.v24i2.206.

31. Moghtaderi A, Bakhshipour A, Rashidi H. Validation of Michigan neuropathy screening instrument for diabetic peripheral neuropathy. Clin Neurol Neurosurg. 2006; 108(5):477-81. doi: 10.1016/j.clineuro.2005.08.003. [PubMed: $16150538]$

32. Timar B, Timar R, Gaiță L, Oancea C, Levai C, Lungeanu D. The impact of diabetic neuropathy on balance and on the risk of falls in patients with type 2 diabetes mellitus: a cross-sectional study. PLoS One. 2016;11(4):e0154654. doi: 10.1371/ journal.pone.0154654. [PubMed: 27119372].

33. Valk GD, Grootenhuis PA, van Eijk JT, Bouter LM, Bertelsmann FW. Methods for assessing diabetic polyneuropathy: validity and reproducibility of the measurement of sensory symptom severity and nerve function tests. Diabetes Res Clin Pract. 2000;47(2):87-95. doi: 10.1016/s0168-8227(99)00111-4. [PubMed: 10670907].

34. Herman WH, Pop-Busui R, Braffett BH, Martin CL, Cleary PA, Albers JW, et al. Use of the Michigan neuropathy screening instrument as a measure of distal symmetrical peripheral neuropathy in Type 1 diabetes: results from the diabetes control and complications trial/epidemiology of diabetes interventions and complications. Diabet Med. 2012;29(7):93744. doi: 10.1111/j.1464-5491.2012.03644.x. [PubMed: 22417277].

35. Armstrong DG, Lavery LA, Vela SA, Quebedeaux TL, Fleischli JG. Choosing a practical screening instrument to identify patients at risk for diabetic foot ulceration. Arch Intern Med. 1998; 158(3):289-92. doi: 10.1001/archinte.158.3.289. [PubMed: 9472210].

36. Simoneau GG, Ulbrecht JS, Derr JA, Becker MB, Cavanagh PR. Postural instability in patients with diabetic sensory neuropathy. Diabetes Care. 1994;17(12):1411-21. doi: 10.2337/ diacare.17.12.1411. [PubMed: 7882810].

37. Brandt Th, Krafczyk S, Malsbenden I. Postural imbalance with head extension: improvement by training as a model for ataxia therapy. Ann N Y Acad Sci. 1981;374:636-49. doi: 10.1111/j.1749-6632.1981.tb30907.x. [PubMed: 6978651].

38. Colberg SR, Sigal RJ, Yardley JE, Riddell MC, Dunstan DW, Dempsey PC, et al. Physical activity/exercise and diabetes: a position statement the American diabetes association. Diabetes Care. 2016;39(11):2065-79. doi: 10.2337/dc16-1728. [PubMed: 27926890].

39. Guney H, Kafa N. Is there any loss of ankle proprioception in diabetic patients without neuropathy. Isokinetics Exer Sci. 2013;21(4):317-23. doi: 10.3233/IES-130503.

40. Aruin AS. Enhancing anticipatory postural adjustments: a novel approach to balance rehabilitation. J Nov Physiother. 2016; 6(2):e144. doi: 10.4172/2165-7025.1000e144. [PubMed: 27335705]

41. Hiroyuki S, Uchiyama Y, Kakurai S. Specific effects of balance and gait exercises on physical function among the frail elderly. Clin Rehabil. 2003;17(5):472-9. doi: 10.1191/0269215503cr638oa. [PubMed: 12952151].

42. Ko S, Simonsick E, Deshpande N, Ferrucci L. Sex-specific age associations of ankle proprioception test performance in older adults: results from the Baltimore Longitudinal Study of Aging. Age Ageing. 2015;44(3):485-90. doi: 10.1093/ageing/afv005. [PubMed: 25637144].

43. Kiers H, Brumagne S, van Dieën J, van der Wees P, Vanhees L. Ankle proprioception is not targeted by exercises on an unstable surface. Eur J Appl Physiol. 2012;112(4):1577-85. doi: 10.1007/s00421-011-2124-8. [PubMed: 21858665].

44. Fortaleza AC, Chagas EF, Ferreira DM, Mantovani AM, Barela JA, Chagas EF, et al. Postural control and functional balance in individuals with diabetic peripheral neuropathy. Rev Bras Cineantropometria Desempenho Humano. 2013;15(3):305-14. doi: 10.5007/1980-0037.2013v15n3p305.

45. Brown SJ, Handsaker JC, Bowling FL, Boulton AJ, Reeves ND. Diabetic peripheral neuropathy compromises balance during daily activities. Diabetes Care. 2015;36(6):1116-22. doi: 10.2337/dc14-1982. [PubMed: 25765355].

46. Hamada SM, Debrky HM. Monitoring of motor function affection and postural sway in patients with type 2 diabetes mellitus. Egyp J Ear Nose Throat Allied Sci. 2014;15(3):241-5. doi: 10.1016/j.ejenta.2014.05.006.

47. Dixit S, Maiya A, Shasthry BA, Kumaran DS, Guddattu V. Postural sway in diabetic peripheral neuropathy among Indian elderly. Indian J Med Res. 2015;142(6):713-20. doi: 10.4103/0971-5916.174562. [PubMed: 26831420].

48. Bloem BR, Allum JH, Carpenter MG, Honegger F. Is lower leg proprioception essential for triggering human automatic postural responses? Exp Brain Res. 2000;130(3):375-91. doi: 10.1007/s002219900259. [PubMed: 10706436].

49. Simmons RW, Richardson C. The effects of muscle activation on postural stability in diabetes mellitus patients with cutaneous sensory deficit in the foot. Diabetes Res Clin Pract. 2001;53(1):25-32. doi: 10.1016/s0168-8227(01)00231-5. [PubMed: 11378210].

50. Kim H. Effect of age and peripheral neuropathy on responses to an unexpected underfoot perturbation during gait. [Doctoral Dissertation]. Michigan: University of Michigan Library; 2012. 